\title{
Cryopreservation of Ribes nigrum (L.) dormant buds: recovery via in vitro culture to the field
}

\author{
Saija Rantala ${ }^{1,2} \cdot$ Janne Kaseva ${ }^{3} \cdot$ Saila Karhu $^{4} \cdot$ Merja Veteläinen $^{5} \cdot$ Marjatta Uosukainen $^{6} \cdot$ Hely Häggman $^{2}$
}

Received: 27 December 2018 / Accepted: 1 April 2019 / Published online: 6 April 2019

(c) The Author(s) 2019

\begin{abstract}
Cryopreservation of dormant buds can be a feasible method for long term preservation of clonally propagated woody plants. In the present study, dormant buds of blackcurrant (Ribes nigrum L) cultivar Mortti were cryopreserved. Twig segments from greenhouse and field grown plants were cooled at their natural moisture content at the rate of $0.17{ }^{\circ} \mathrm{C} \mathrm{min}^{-1}$ from zero to $-38{ }^{\circ} \mathrm{C}$, immersed in liquid nitrogen and stored in liquid nitrogen vapor. The post-cryopreservation regrowth of buds was evaluated in vitro and viability of recovered plants was tested in vivo. The estimated recovery rate for buds thawed after 1-6 days in cryostorage was $86 \%$ and $66 \%$ for outdoor and greenhouse grown buds, respectively. Microplants adequate in size and quality grew successfully in vivo and plants produced berries in field. After 4 years in cryostorage, the estimated recovery rate for outdoor buds was 58\%. According to results from 1 to 6 days cryostorage, the tested dormant bud protocol turned to be applicable for cryopreservation of the blackcurrant cultivar Mortti. However, concerning the long-term preservation the decline of recovery is important to consider in the future experiments.
\end{abstract}

\section{Key message}

The cryopreservation of dormant buds combined with in vitro recovery provides a feasible tool for conservation of plant genetic resources of blackcurrant.

Keywords Blackcurrant $\cdot$ Cryostorage $\cdot$ Gene bank $\cdot$ Germplasm $\cdot$ Micropropagation

\section{Introduction}

Genetic resources of clonally propagated plants can be maintained in field-collections or in greenhouses, in vitro, or as cryopreserved propagules at ultra-low temperatures

Communicated by Qiao-Chun Wang.

Saija Rantala

saija.rantala@luke.fi

Janne Kaseva

janne.kaseva@luke.fi

Saila Karhu

saila.karhu@luke.fi

Merja Veteläinen

merja.vetelainen@boreal.fi

Marjatta Uosukainen

marjatta.uosukainen@outlook.com

Hely Häggman

hely.haggman@oulu.fi ca. $-196{ }^{\circ} \mathrm{C}$ to $-150{ }^{\circ} \mathrm{C}$ in liquid or vapour phase nitrogen (FAO 2013). In field collections plants are exposed to diseases, pests and extreme weather conditions, which can jeopardize the maintenance of collection. To secure the preservation of genetic resources, cryopreservation is recommended as a backup collection alongside field or in vitro stored collections (Reed et al. 2004a).

1 Production Systems, Natural Resources Institute Finland (Luke), Survontie 9A, 40500 Jyväskylä, Finland

2 University of Oulu, Faculty of Science, Ecology and Genetics Unit, P.O.Box 3000, 90014 Oulu, Finland

3 Natural Resources, Natural Resources Institute Finland (Luke), Tietotie 4, 31600 Jokioinen, Finland

4 Production Systems, Natural Resources Institute Finland (Luke), Itäinen Pitkäkatu 4 A, 20520 Turku, Finland

5 Boreal Plant Breeding Ltd., Myllytie 10, 31600 Jokioinen, Finland

6 MTT Agrifood Research Finland, Antinniementie 1, 41330 Vihtavuori, Finland 
Different cryopreservation protocols are available for diverse types of plant material (Reed 2008). For cold hardy woody plants, cryopreservation of dormant buds can be a feasible method. However, the source material chosen for cryopreservation should be as healthy and viable as possible to ensure the success of cryopreservation and utilization of regenerated plants (FAO 2013). After cryopreservation, a small number of propagules are usually thawed to evaluate recovery success. All factors of in vitro culture influence the success of the protocol (Reed 2017). However, the efficiency of the preservation process depends also on the subsequent steps of cultivation.

The most important factors for the success of dormant bud cryopreservation are the cold acclimation ability of the species and the state of cold acclimation of the plant material at the time of the collection (Towill and Ellis 2008). The first studies of dormant bud cryopreservation (Sakai 1960) demonstrated that if twigs of winter hardy willow and poplar were slowly pre-cooled until $-30{ }^{\circ} \mathrm{C}$, they were able to survive the exposure to liquid nitrogen. Sakai (1960) concluded that at around $-30{ }^{\circ} \mathrm{C}$ almost all easily freezable water in a cell may be drawn from cell interior by extracellular freezing; therefore cells and tissues are not injured. Subsequent studies have further shown that desiccation of twigs prior to slow cooling improves cryo-survival of buds (e.g. Tyler and Stushnoff 1988a, b) but it might not always be necessary (Towill \&Widrlechner 2004; Towill \& Bonnart 2005). In addition to cold acclimation and moisture content of the source material, the success of the protocol is influenced by the cooling rate, thawing method, and regrowth procedure (Towill and Ellis 2008; Reed 2011; Benelli et al. 2013; Stushnoff 2014). The recovery of buds after cryopreservation can be done directly in vivo or via culturing in vivo.

The steps for dormant bud cryopreservation vary according to source material and recovery method. According to protocol developed by Forsline et al. (1998), twigs are desiccated to the moisture content about $30 \%$, cooled at $1{ }^{\circ} \mathrm{C}$ $\mathrm{h}^{-1}$ from $-4{ }^{\circ} \mathrm{C}$ to $-30{ }^{\circ} \mathrm{C}$ and held at $-30{ }^{\circ} \mathrm{C}$ for $24 \mathrm{~h}$ before storage in liquid nitrogen. This protocol is generally used with Malus (e.g. Volk et al. 2008; Grout et al. 2011; Lambardi et al. 2011; Höfer 2015; Höfer and Hanke 2017) and also applied for Salix (Towill and Widrlechner 2004; Jenderek et al. 2014) Fraxinus (Volk et al. 2009) Juglans, Prunus, (Jenderek et al. 2014) and Vaccinium (Jenderek et al. 2017). Protocols where recovery of buds is done via in vitro culture have been developed e.g. for Morus (Yakuwa and Oka 1988,) Pyrus (Oka et al. 1991), Betula (Ryynänen 1996), Diospyros (Matsumoto et al. 2004), Populus (Jokipii et al. 2004,) and Ulmus (Harvengt et al.2004). The effects of different pre-treatment combinations and cryoprotectants for dormant bud cryopreservation have also been investigated (Kovalchuk et al. 2014; Zhumagulova et al. 2014).
Blackcurrant (Ribes nigrum L.) is a woody perennial shrub found from Europe to Central Asia and Himalayas (Rehder 1940). Blackcurrant berries are generally considered to be a part of healthy diet and are used for food products like juices and jams. In commercial berry production varieties originating from breeding programs are used. Many old blackcurrant varieties and local strains are no longer in cultivation, but they can be valuable sources for plant breeding (Mattila et al. 2016). Cryopreservation of blackcurrants is generally done using in vitro cultures as source material (Benson et al. 1996; Reed et al. 2001; 2004b, 2005; Sherlock et al. 2005; Johnston et al. 2007). Green and Grout (2010) showed that recovery of dormant buds of blackcurrant after direct cryopreservation is possible via in vitro culture, but due to injuries caused by cryopreservation, the recovery of buds through grafting did not succeed. However, even if the recovery of buds is done in vitro, the cryopreservation of dormant buds is simpler process than the use of isolated meristems with cryoprotectants (Yakuwa and Oka 1988). Moreover, when buds are recovered in vitro, a smaller number of cryopreserved buds may be needed in comparison to in vivo recovery, as the regenerated plants can be multiplied via micropropagation after cryopreservation.

In 2007, the multinational four-year project RIBESCO was initiated to improve the characterisation and conservation of the North and Central European Ribes germplasm (Karhu et al. 2012). In Finland, a new field collection of blackcurrant was established because of reversion virus induced symptoms detected in the old germplasm collection. Alongside the new collection, a cryopreserved backup collection was established. The aim of the present study was to investigate the characteristics that might affect post-cryopreservation recovery of dormant blackcurrant buds in vitro and regrowth of microplants in vivo. The cryopreservation of both indoor and outdoor grown plants was tested, and the suitability of the protocol for the long-term preservation of blackcurrant was evaluated.

\section{Materials and methods}

\section{Plant material}

The study was performed in Laukaa in Central-Finland (62 ${ }^{\circ} 19^{\prime} 13^{\prime \prime}$ N, $25^{\circ} 59^{\prime} 36^{\prime}$ ' E). Dormant buds of blackcurrant cultivar Mortti were collected from four greenhousegrown and four field-grown plants in the middle of January 2011. All plants were clones from the same original accession and originated from virus- tested material. The outdoor shrubs were planted in 2002 for true-to-type testing and pruned down in spring 2009. The virus-tested stock plants maintained in greenhouse had been planted in 2007 and were pruned annually. The cold acclimation 
history of the indoor and outdoor plants was very different: during the winter season the lowest temperature in the field was about $-32{ }^{\circ} \mathrm{C}$ and in the greenhouse $+2{ }^{\circ} \mathrm{C}$. At the time of collection of the branches, temperature was $-5{ }^{\circ} \mathrm{C}$ in the field and $+4{ }^{\circ} \mathrm{C}$ in the greenhouse. After collection, the branches were wrapped in plastic bags and stored in cold room $\left(+2{ }^{\circ} \mathrm{C}\right)$ until the following day.

\section{Cryopreservation}

Altogether 80 indoor and 80 outdoor buds, twenty buds from each study plant, were cryopreserved for the study. In addition, 156 outdoor buds, 39 from each outdoor plant, were cryopreserved at the same time for long-term cryostorage. Long-term cryostorage of indoor buds was not possible due to shortage of material. To accelerate the cryopreservation process, buds were cryopreserved without pre-desiccation of twigs according to Ryynänen et al. (2008), based on successful cryopreservation of silver birch (Betula pendula Roth) (Ryynänen 1996, 1999; Ryynänen et al. 2002) and hybrid aspen (Populus tremula L x P. tremuloides Minchx) (Jokipii et al. 2004) with this method. Approximately $2-\mathrm{cm}$ long twig segments with one axillary bud were cut from shoots. The basal and uppermost part of the shoots were not used. No selection between bud types was made before cryopreservation because bud type (vegetative or floral) was not possible to determine in the case of intact buds. The twig segments were sealed in $1.8 \mathrm{ml}$ cryovials (Sarstedt, Nümbrecht Germany) and stored in cryoboxes (Sarstedt, Nümbrecht Germany) at $\pm 0{ }^{\circ} \mathrm{C}$ overnight.

Next day the cryovials were cooled at rate of $0.17^{\circ} \mathrm{C}$ per min from zero to $-38{ }^{\circ} \mathrm{C}$ using a controlled rate freezer (Planer Kryo 10-16 series II with controller module Kryo 10-22, Planer products Ltd., England). The vials were kept at $-38{ }^{\circ} \mathrm{C}$ for about 40 min before being immersed in liquid nitrogen and stored in the vapor phase of liquid nitrogen in the cryotank (MVE 1520 Eterne with TEC 2000 system monitor, CHART/MVE Applied Technologies, Biological Systems, Minnesota). The moisture content of twig samples representing each donor plant was determined gravimetrically and expressed on a freshweight basis (Forsline et al.1998). The twig samples with known fresh weights were oven dried at $+85^{\circ} \mathrm{C}$ for two days. Both fresh and dry weights of twigs were determined by using a balance scale (Mettler PM 4600 Delta range ${ }^{\circledR}$, Columbus, Ohio).

\section{The recovery of buds in vitro}

The buds were thawed after $1,2,5$ or 6 days of cryopreservation. Forty buds, twenty from one outdoor and twenty from one indoor donor plant were thawed per day. Cryovials containing twigs were thawed in a water bath at $+37{ }^{\circ} \mathrm{C}$ for $3 \mathrm{~min}$. The buds were surface sterilized by soaking twigs in $70 \%$ ethanol for about $20 \mathrm{~s}$ and thereafter quickly dipped in pure ethanol. The bud lengths were measured under a stereomicroscope and the bud type, vegetative or floral, was recorded, as both size and type of bud is known to affect the cryosurvival of buds. The innermost part of the buds containing some primary leaves was dissected from the twigs and the explants were placed in test tubes on WPM culture media (Lloyd and McCown 1980) supplemented with $6.84 \mu \mathrm{M}$ zeatin and $20 \mathrm{~g} \mathrm{l}^{-1}$ sucrose, adjusted to $\mathrm{pH} 5.2$ and solidified with the mixture of agars (4.375 $\mathrm{g} \mathrm{l}^{-1}$ Scharlau Agar and $4.375 \mathrm{~g} \mathrm{l}^{-1}$ Carl Roth Agar). Explants in the test tubes were placed in a growth room at $+22{ }^{\circ} \mathrm{C}$ and kept in dark for 7 days before exposed to a $16 / 8 \mathrm{~h}$ light/dark photoperiod under two fluorescent tubes (Osram L 36 W/830 Lumilux warm white, Germany), with photosynthetically active radiation on average $60 \mu \mathrm{mol} \mathrm{m} \mathrm{m}^{-2} \mathrm{~s}^{-1}$ ).

Two and a half weeks after initiation of recovery, the explants were transferred from test tubes to $25 \mathrm{ml}$ Erlenmeyer flasks containing semisolid $\mathrm{G}$ basal media (Uosukainen 1992) supplemented with $3.33 \mu \mathrm{M}$ 6-benzyladenine and $20.0 \mathrm{~g} \mathrm{l}^{-1}$ fructose. The media was adjusted to $\mathrm{pH} 5.0$ before autoclaving and solidified with the mixture of agars described above. Thereafter, explants were subcultured every 3 weeks using $50 \mathrm{ml}$ Erlenmeyer flasks as culture vessels. At the beginning of the in vitro culture of blackcurrant, the initiation point of shoot outgrowth was carefully observed and shoots with a suspected outgrowth point were not accepted for further cultivation. Moreover, twenty noncryopreserved control buds from both greenhouse and from field-five from each donor plant-were cultivated in vitro along with the cryopreserved buds.

The recovery of buds was evaluated 11 weeks after initiation of the in vitro culture. The buds that produced at least one viable shoot were considered as recovered. Shoots were evaluated by visually inspecting necrosis and the number of translucent or brittle leaves indicating hyperhydricity (Debergh et al. 1992). The quality of shoots was graded for extent of visible signs of necrosis or hyperhydricity $(1=$ entirely, $2=$ plenty, $3=$ slightly, $4=$ no signs $)$. The number of shoots per bud was counted and the tallest shoot per bud was measured (stem length $\mathrm{mm}$ ). Finally, the buds were classified according to the performance of the produced shoots (based on the number and quality of shoots sprouted from the bud) $(0=$ dead bud, $1=$ one non-viable shoot, $2=$ one or two fragile shoots, $3=$ one good shoot and some fragile shoots, $4=$ two to four good shoots, $5=$ five or more good shoots). 


\section{Growth of plants in vivo}

To evaluate the efficiency of the whole recovery process, the viability of recovered shoots was tested in vivo. For the in vivo cultivation, shoots were grouped into 30 groups according their size and original donor plant. The shoots derived from cryopreserved buds were first grouped into eight groups according to their donor plant. The control shoots were divided into two groups according to the growth site of their donor plant (indoor or outdoor). Thereafter, the shoots of these 10 groups were subdivided into three groups according to their size (i.e. stem height and sturdiness). The three size groups were: 1) small, slender shoots with a height of 5-10 mm, 2) mid-sized, firmer shoots $10 \mathrm{~mm}$ in height, and 3) sturdy shoots with a height of $15 \mathrm{~mm}$ or more. Before planting, the basal parts of shoots were dipped in indole3-butyric acid potassium salt, (100 mg/l, KIBA Sigma) to promote root formation. After planting, the stem length of the shoots was shorter than the original planting size because the basal part of the stems was submerged into the peat.
The shoots were planted in 15 propagator boxes filled with a mixture of Sphagnum peat, soil and sand (2:1:0.4) and the surface covered with sand. Boxes of three sizes were used according to the size of the shoots. Altogether forty shoots, twenty recovered from indoor buds and twenty from outdoor buds, were planted in each box (Fig. 1c). If the number of the recovered shoots was less than twenty, the group was supplemented with control shoots of appropriate size in order to ensure equal competition between plants. After planting, the quality of shoots was evaluated according to their leaves - brittle and translucent or not - to detect visible signs of hyperhydricity. Propagator boxes were placed in a growth room at $+21^{\circ} \mathrm{C}$ under fluorescent tubes (Sylvania Gro lux F36 W/GRO T8, Germany) with a 16/8 h light/dark photoperiod. Shoots were gradually acclimatized to in vivo conditions and transferred to the greenhouse 4 weeks after planting in the beginning of May and thereafter cultivated according to the conventional greenhouse procedure. In greenhouse, artificial light was used to supplement natural spring time light.

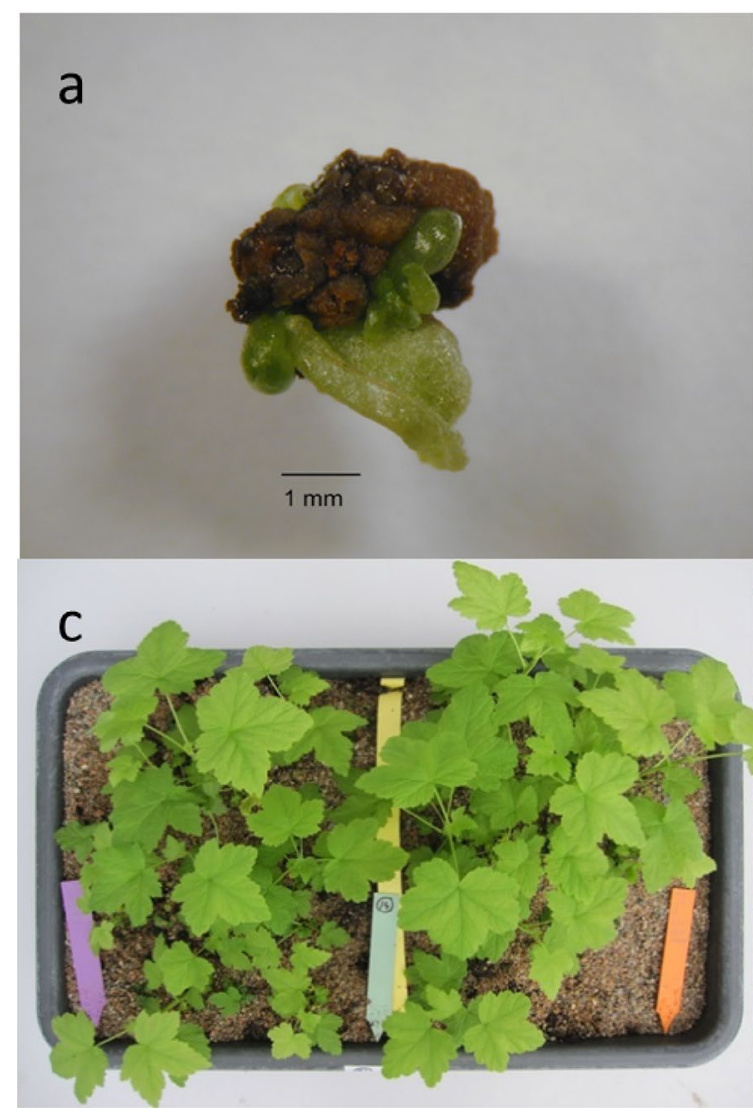

Fig. 1 a Cryopreserved floral bud of the blackcurrant cv. Mortti 4 weeks after initiation of in vitro culture. The flower primordia and basal parts of the bud have turned dark (photo Dr Mauritz Vestberg). b Plantlets in Erlenmeyer flasks 11 weeks after the initiation of in vitro culture; control material on the left and shoots from cryopre-

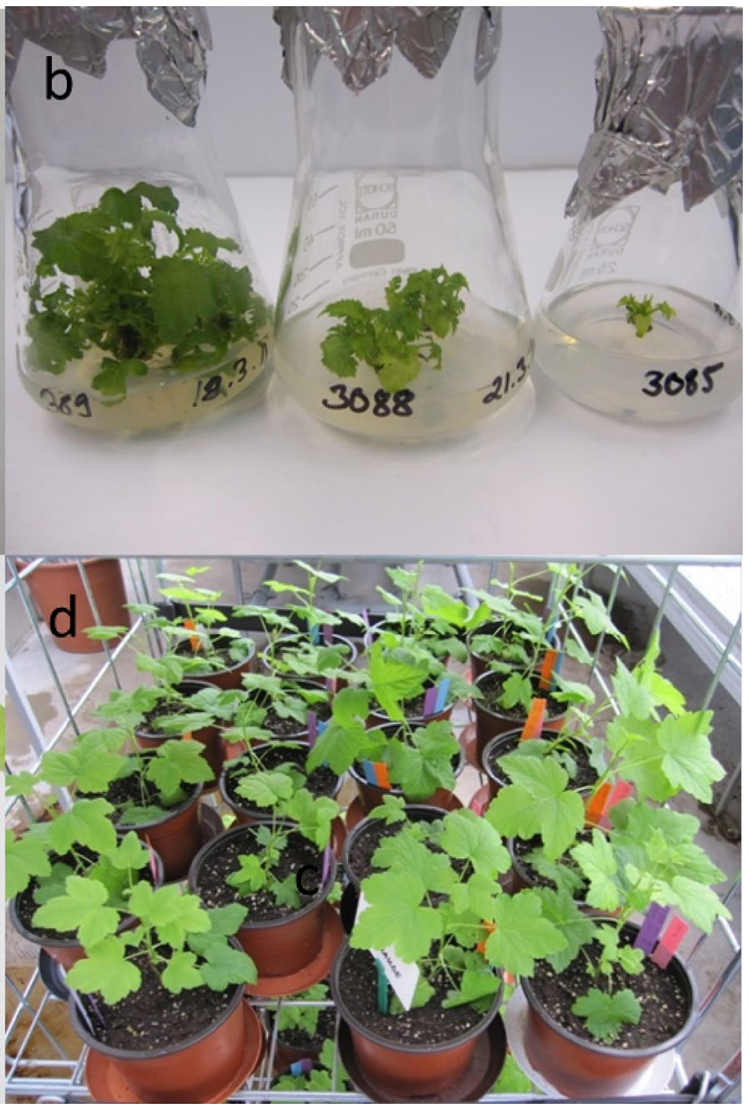

served buds in two vials on the right. $\mathbf{c}$ Plants belonging to the planting-size "mid-sized" 9 weeks after planting in vivo. Plants recovered from the cryopreserved outdoor buds on the left and plants recovered from the cryopreserved indoor buds on the right. $\mathbf{d}$ Potted plants to be tested in further cultivation 
The survival and growth of shoots in vivo was recorded 9 weeks after planting. To evaluate the size of the plants, the stem length ( $\mathrm{mm}$ above ground), the number of leaves and the length of the biggest leaf $(\mathrm{mm})$ were recorded. Plants were classified according to their utility for further cultivation (based their size and quality) $(0=$ dead, $1=$ very poor, $2=$ poor, $3=$ passable, $4=$ good, $5=$ excellent). Some of the plants were potted for further cultivation (Fig. 1d) and altogether 16 plants, four cryopreserved and four control plants recovered from both indoor and outdoor buds, were planted in field in the beginning of October 2011. The berries of those plants were harvested in autumn 2014 and 2015.

\section{Recovery of buds after 4 years in cryostorage}

To test the long-term cryostorage survival of cv. Mortti buds, forty outdoor buds were thawed after 4 years of cryostorage in spring 2015. These forty buds were cryopreserved at the same time as buds thawed in 2011 and they were recovered in vitro according to the same procedure and by the same personnel as in 2011. However, the recovered shoots were not transplanted in vivo. In addition, ten outdoor buds were thawed for more detailed monitoring. These buds were kept in dark for only one day, followed by one day in dim light, and observed also during the first days of the in vitro culture.

\section{Statistical analysis}

The relations between the estimated recovery rate and explanatory variables were studied by contingency tables. In the case of categorical variables (growth site of donor plant, bud type, treatment, planting size of shoot and hyperhydricity) the Chi square test was used. The Fisher's exact test was used when one or more of cells had an expected frequency of five or less. The Cochran-Mantel-Haenszel test was used when the explanatory variable was ordinal (the size of bud).

For statistical analysis variables with unevenly distributed classes were reclassified from the scale of $1-5$ to a binary scale (for example $0=1-3$ and $1=4-5$ ) to improve the power of the test. For example, in the case of the variable "performance of the produced shoots", the original classes were combined so that classes $1-3=0$ (the bud produces none or only one viable shoot) and classes $4-5=1$ (the bud produced at least two or more viable shoots), the latter class being a good start for multiplying shoot cultures. Other reclassified variables were "necrosis" and "hyperhydricity" and "the utility of in vivo cultured plants for further cultivation" ("dead to poor plants" versus "passable to excellent"). The estimated recovery rate in vitro, the number of shoots sprouted from a bud, the length of the highest shoot, the probability that bud produces at least two viable shoots and the survival of shoots in vivo were modelled by generalized linear mixed models (GLMM). The assumptions of normal, lognormal and Bernoulli (for binary responses) distributions for the responses were used in the analysis. Partially based on previous contingency table analysis treatment, bud type, the size of bud, and all their interactions were denoted as fixed effects. Donor plant was used as a random effect.

The models were fitted by using the residual maximum likelihood (REML) estimation method. Degrees of freedom were calculated using the Kenward-Roger method. The residuals were checked for normality using boxplot and normal probability plot. These plots indicated that the assumptions of the models were adequate. The Tukey-Kramer post hoc test was used in pairwise comparison of means. A statistical significance level of $\alpha=0.05$ was used in all analyses. Statistical analysis was conducted using SAS Enterprise Guide 6.1 (SAS Institute Inc., Cary, NC, USA).

\section{Results}

\section{Plant material}

The buds of cultivar Mortti differed in size and bud type (floral or vegetative) according to the growth site of donor plants. The outdoor buds were bigger than indoor buds on average. The mean length of outdoor buds was $4.7 \mathrm{~mm}$ for control buds, $4.6 \mathrm{~mm}$ for buds thawed in 2011 and $5.3 \mathrm{~mm}$ for buds thawed in 2015. The mean length of indoor buds was $1.3 \mathrm{~mm}$ for control buds and $2.4 \mathrm{~mm}$ for buds thawed in 2011. Among outdoor buds, almost all buds thawed in 2011 (77/80) and all control buds and buds thawed in 2015 were floral. About half of indoor buds thawed in 2011 (39/80) were floral but only one $(1 / 20)$ of control buds. The moisture content of twig samples was $55-58 \%$ for outdoor and $56-58 \%$ for indoor plants. The number of contaminations during the in vitro culture after thawing was minor-only one bud was omitted due contamination in 2011.

\section{Recovery in vitro}

In 2011, the recovery of cryopreserved buds differed according to growth site of the donor plant, but not according to the number of days in cryopreservation. The estimated recovery rate of buds was higher for outdoor than indoor buds (Table 1). However, after 4 years cryostorage, the estimated recovery rate of outdoor buds had decreased significantly (Table 1). After 1-6 days of in cryostorage, the estimated recovery rate for floral buds was $81 \%$ and for vegetative buds $65 \%$, but the difference was not statistically significant $(\mathrm{p}=0.064)$.

At the time of initiation of in vitro cultures, the cryopreserved buds were wholly green, but during 7 days in 
Table 1 The estimated average recovery rate (\%) in vitro for the dormant indoor and outdoor blackcurrant buds (cv. Mortti) after 1-6 d and 4 years cryostorage. Indoor buds were collected from greenhouse and outdoor buds from field. Non-cryopreserved buds were used as controls

\begin{tabular}{llll}
\hline Bud groups & $\mathrm{N}$ & $\begin{array}{l}\text { The estimated } \\
\text { recovery } \\
\text { rate } \%\end{array}$ & $\mathrm{CI}$ \\
\hline $\begin{array}{llll}\text { Indoor buds after 1 to 6 d cryostorage } \\
\text { Outdoor buds after 1 to 6 d cryostor- }\end{array}$ & $\begin{array}{l}80 \\
\text { age }\end{array}$ & $86^{\mathrm{a}}$ & $55-76$ \\
Outdoor buds after 4 years cryostorage & 40 & $58^{\mathrm{a}}$ & $76-93$ \\
Control buds in vitro 2011 & 40 & $95^{\mathrm{b}}$ & $41-73$ \\
\hline
\end{tabular}

${ }^{\mathrm{a}, \mathrm{b}}$ Different superscript letters indicate significant differences $(\mathrm{p}<0.05)$ in estimated recovery rate in vitro between bud groups and treatment

$n$ the number of the buds initiated for in vitro culture. Number of control buds is combination of buds from greenhouse $(n=20)$ and from outdoors $(\mathrm{n}=20)$. CI Confidence intervals. Fisher's exact test was used

darkness the flower primordia or primordial leaves on the top of the dissected bud explants had turned pale or grey. Monitoring of those ten buds thawed in 2015 and kept in darkness only one day, revealed that primordial leaves and flower primordia turned pale within a day. After cryopreservation, the first leaves started to grow within 2 weeks and shoots emerged from buds within 4 weeks. For both vegetative and flower buds, the growth of shoots started from axillary buds of the dissected bud explants.

The cryopreserved buds produced less and smaller shoots than the non-cryopreserved control buds (Fig. 1b, Table 2). The probability (\%) that a bud would produce at least two viable shoots in 11 weeks of in vitro culture was significantly less for cryopreserved buds than for control buds (Table 2). However, there were no significant differences in the number of shoots per bud or the height of the tallest shoots between cryopreserved indoor and outdoor buds in 2011 or between cryopreserved outdoor buds in 2011 and 2015 (data not shown).

All cryopreserved buds were more prone to necrosis than the control ones (Fig. 1a). In the case of cryopreserved buds, most of the emerging shoots were eventually dissected from the basal part of the bud explants because of necrosis. At the end of the in vitro culture, necrosis (classes 2 or 3 ) was present in $12 \%$ of shoots recovered from cryopreserved buds but was not observed in control shoots $(\mathrm{p}=0.023)$. Hyperhydricity of leaves (classes 1-3) was, however, more common among control shoots (90\%) than in shoots recovered from cryopreserved buds $(45 \%)(p=0.001)$. Significant differences could not be found between cryopreserved indoor and outdoor buds when considering the necrosis or hyperhydricity of recovered shoots (data not shown).

\section{Survival in vivo}

The original planting-size of the shoots had a major effect on survival in vivo. The survival of shoots in planting-size "sturdy", "mid-sized" and "small was 75, 60 and 36\% for shoots originating from indoor buds (indoor shoots) and 70, 58 and $21 \%$ for shoots originating from outdoor buds (outdoor shoots), respectively. Because the number of shoots that survived in the planting size-group "small" was very low, they were excluded from further statistical analyses. When only groups "mid-sized" and "sturdy" were tested, the estimated survival rate was significantly higher for shoots with no visible symptoms of hyperhydricity than for shoots with translucent leaves at the time of planting (Table 3). The estimated survival rate of the shoots was significantly better also for shoots belonging planting-size "sturdy" than "mid-sized" and for cryopreserved than for control shoots (Table 3).

\section{Shoot growth in vivo}

The in vivo growth of the shoots varied greatly. Some microplants did not elongate at all during the first 9 weeks in vivo whereas the stem length of the highest plant was $21.4 \mathrm{~cm}$ at the time of evaluation. Thus, while the mean stem height of plants was $9.7 \mathrm{~mm}$ for cryopreserved and $22.5 \mathrm{~mm}$ for control plants, the difference was not significant due to large standard errors $(\mathrm{p}=0.137)$. The estimated number of leaves for cryopreserved and for control plants was 9.4 and 11.7, respectively $(\mathrm{p}=0.067)$. The estimated variable "length of
Table 2 The estimated average shoot proliferation from the cryopreserved and noncryopreserved blackcurrant cv. Mortti buds, the height of the highest stem and the estimated probability that a bud produces at least two viable shoots during 11 weeks of in vitro cultivation

\begin{tabular}{|c|c|c|c|c|c|c|c|}
\hline \multirow[b]{2}{*}{ Estimated variables } & \multicolumn{3}{|c|}{ Cryopreserved bud } & \multicolumn{3}{|c|}{ Control bud } & \multirow[b]{2}{*}{$p$ value } \\
\hline & $\mathrm{N}$ & Value & CI & $\mathrm{N}$ & Value & CI & \\
\hline Number of shoots per bud & 120 & 3.6 & $3.2-4.1$ & 39 & 5.5 & $4.5-6.7$ & $<0.001$ \\
\hline $\begin{array}{l}\text { The height of the highest } \\
\text { shoot in bud (mm) }\end{array}$ & 118 & 6.4 & $5.6-7.2$ & 37 & 10.7 & $9.6-11.8$ & $<0.001$ \\
\hline $\begin{array}{l}\text { Probability (\%) of at least two } \\
\text { viable shoots per bud }\end{array}$ & 121 & 60 & $47-71 \%$ & 39 & 85 & $69-93 \%$ & 0.015 \\
\hline
\end{tabular}

CI Confidence intervals 
Table 3 The estimated survival of micropropagated shoots of the blackcurrant cv. Mortti in vivo according to their planting size and the quality of leaves (with or without visible signs of hyperhydricity at the time of planting) and treatment of the bud (cryopreserved or not) whereof the shoot was initiated in vitro. Comparisons were done for binary responses

\begin{tabular}{llll}
\hline $\begin{array}{l}\text { Characteristics of micropropagated shoots at the time of } \\
\text { planting }\end{array}$ & $\mathrm{N}$ & $\begin{array}{l}\text { The estimated survival } \\
\text { in vivo } \%\end{array}$ & CI value \\
\hline Leaves with signs of hyperhydricity & 81 & 47 & $36-59$ \\
No visible signs of hyperhydricity & 261 & 67 & $60-73$ \\
Stem height $10-14 \mathrm{~mm}$ & 196 & 51 & $43-59$ \\
Stem height $\geq 15 \mathrm{~mm}$ & 146 & 64 & $54-73$ \\
Shoots sprouted from cryopreserved bud & 262 & 64 & $57-71$ \\
Shoots sprouted from control bud & 80 & 50 & $38-62$ \\
\hline
\end{tabular}

CI Confidence intervals

the biggest leaf" was higher for the control than for the cryopreserved plants (data not shown).

After 9 weeks in vivo, the interaction between the planting size of the shoots (mid-size or sturdy) and the growth site (indoor or outdoor) of donor plants was significant for all three variables measured (the number of the leaves; $p=0.007$, the height of the stems; $p=0.035$, and the length of the biggest leaf; $p=0.046$ ). The paired comparisons between shoot groups according to the stem height and the number of leaves are shown in Table 4. "The sturdy indoor plants" had more leaves $(\mathrm{p}<0.001)$ and higher stems $(\mathrm{p}=0.008)$ than "sturdy outdoor plants" (Table 4). Nine weeks after planting in vivo, there were no significant differences in the stem height or the number of the leaves between sturdy and mid-sized indoor shoots or between sturdy and mid-sized outdoor shoots. However, the "sturdy indoor shoots" had more leaves than "mid-sized outdoor shoots" $(p=0.024)$ (Table 4). The paired comparisons of the variable "the length of the biggest leaf" showed no significant differences between the shoot groups (data not shown).

The utility of plants for further cultivation was affected by the interaction between planting-size of the shoots and growth site of the donor plant ( $\mathrm{p}=0.018)$. In planting-size "sturdy", there were more plants eligible for cultivation

Table 4 The estimated values for stem height and the number of the leaves of micropropagated shoots of the blackcurrant cv. Mortti according to original planting-size in vivo and growth place of the

\begin{tabular}{|c|c|c|c|c|c|c|}
\hline \multirow[t]{2}{*}{ Planting-size of shoots } & \multirow{2}{*}{$\begin{array}{l}\text { Growth site of donor } \\
\text { plant }\end{array}$} & \multirow[b]{2}{*}{$\mathrm{N}$} & \multicolumn{2}{|c|}{ Stem height (mm) } & \multicolumn{2}{|c|}{ The number of the leaves } \\
\hline & & & Median & CI & Mean & CI \\
\hline Sturdy & Outdoor & 60 & $7.4^{\mathrm{b}}$ & $3.3-16.3$ & $9.3^{\mathrm{b}}$ & $7.5-11.1$ \\
\hline Sturdy & Indoor & 46 & $28.3^{\mathrm{a}}$ & $12.6-63.5$ & $12.8^{\mathrm{a}}$ & $10.9-14.6$ \\
\hline Mid-size & Outdoor & 57 & $13.3^{\mathrm{ab}}$ & $6.0-16.3$ & $9.7^{\mathrm{b}}$ & $7.9-11.5$ \\
\hline Mid-size & Indoor & 59 & $17.2^{\mathrm{ab}}$ & $7.8-38.2$ & $10.5^{\mathrm{ab}}$ & $8.7-12.3$ \\
\hline
\end{tabular}

${ }^{\mathrm{a}, \mathrm{b}}$ Different superscript letters indicate significant differences $(\mathrm{p}<0.05)$

CI confidence intervals among plants recovered from indoor buds (59\%) than from outdoor buds $(25 \%)(\mathrm{p}=0.014)$.

All cryopreserved and control plants planted in the field in autumn 2011 showed normal growth during successive years. Visual inspection indicated that their appearance was typical of cultivar Mortti plants. The total yield of berries in 2014 and 2015 varied by plants in treatments but the means of total yield and the weights of 100 berries in diverse groups were on a similar level (Table 5).

\section{Discussion}

Dormant bud technique is applied for many species and different protocols used (e.g. Yakuwa and Oka 1988; Ryynänen 1996; Forsline et al. 1998; Harvengt et al. 2004; Matsumoto et al. 2004; Jenderek et al. 2017). In the present study, we investigated characteristics that might affect post-cryopreservation recovery of dormant blackcurrant buds in vitro and the regrowth of shoots in vivo. For the study, dormant buds were collected both from greenhouse and field grown plants. Success of cryopreservation of indoor buds is of special interest because the virus tested stock plants maintained in greenhouse would be good source material for long term cryopreservation if the cold acclimation of the plants is

donor plant (i.e. whereof the bud was collected) after 9 weeks in vivo. The responses of stem height were lognormally distributed 
Table 5 The mean yields and mean weights of 100 berries of the blackcurrant cv. Mortti plants in 2014 and 2015. The plants were initiated in 2011 from cryopreserved and control buds collected from field or greenhouse and cultivated through micropropagation

\begin{tabular}{|c|c|c|c|c|c|}
\hline \multirow[t]{2}{*}{ Plants initiated from buds } & \multirow[t]{2}{*}{$\mathrm{N}$} & \multicolumn{2}{|c|}{ Mean and range in 2014} & \multicolumn{2}{|c|}{ Mean and range in 2015} \\
\hline & & Total yield (g) & $\begin{array}{l}\text { Weight of } \\
100 \text { berries } \\
(\mathrm{g})\end{array}$ & Total yield (g) & $\begin{array}{l}\text { Weight of } \\
100 \text { berries } \\
\text { (g) }\end{array}$ \\
\hline Cryopreserved, from field & 4 & $595(245-774)$ & $71(66-75)$ & $506(238-800)$ & $49(42-61)$ \\
\hline Control, from field & 4 & $602(322-870)$ & $73(68-78)$ & $317(206-522)$ & $53(42-63)$ \\
\hline Cryopreserved, from greenhouse & 4 & $527(292-715)$ & $74(66-78)$ & $365(227-585)$ & $46(40-59)$ \\
\hline Control, from greenhouse & 4 & $426(404-463)$ & $71(61-80)$ & $372(305-415)$ & $48(40-60)$ \\
\hline
\end{tabular}

shown to be adequate for cryopreservation. The implementation of the protocol would also be easier to standardize in greenhouse where variation in growth conditions between years is usually minor. Moreover, the risk of contaminations related to initiation of in vitro cultures would be lower for buds collected from greenhouse than from outdoor (Niedz and Bausher 2002; Aronen and Ryynänen 2014). According to our results, the post-cryopreservation recovery was better for outdoor than for indoor buds, but in both cases, buds produced viable plants that yielded berries when planted in field.

The better recovery of outdoor buds was expected, as the importance of cold acclimation for the successful cryopreservation is well known. The plants maintained in greenhouse were not exposed to sub-zero temperatures, so the extent of cold acclimation was less for indoor than for outdoor buds. In previous studies, donor plants of transgenic silver birch (Ryynänen et al. 2002) and hybrid aspen (Jokipii et al. 2004) were transferred from greenhouse into dark cold storage at $+2{ }^{\circ} \mathrm{C}$ for 2 months before buds were collected for cryopreservation. In the case of blackcurrant cv. Mortti, the temporary transfer of virus tested stock plants from isolated greenhouse to the cold room was not possible because of the phytosanitary requirements in certified plant production. With hybrid aspen, the cryopreservation of dormant buds was successful also when buds were collected directly from greenhouse (Aronen and Ryynänen 2014). The importance of pre-harvest temperature for cryopreservation success is presumably dependent on both the protocol and the species. For instance, according to Jenderek et al. (2017) the optimal bud-harvest time for blueberry (Vaccinium L.) would be after a 10 day period in the average maximum temperature less than $+11.2^{\circ} \mathrm{C}$. However, in the case of blueberry, buds were desiccated at $-5{ }^{\circ} \mathrm{C}$ before slow cooling to $-30{ }^{\circ} \mathrm{C}$, which may have substituted an artificial cold acclimation treatment.

Both indoor and outdoor scions of cv. Mortti were stored overnight at $+2{ }^{\circ} \mathrm{C}$ before cutting the twigs. An identical temperature regime may either cause cold acclimation or cold de-acclimation, depending on the temperature to which the plant was previously exposed to (Kalberer et al. 2006). Thus, it is possible that overnight storage at $+2{ }^{\circ} \mathrm{C}$ caused cold de-acclimation of outdoor buds but had only a minor effect on cold acclimation of indoor buds. According to Toldam-Andersen et al. (2007), a 2 week pre-treatment of outdoor scions at $-4{ }^{\circ} \mathrm{C}$ before desiccation of twigs at $-4{ }^{\circ} \mathrm{C}$ did not affect the average survival rates of Malus buds and also the 2 week cold de-acclimation treatment at $+5{ }^{\circ} \mathrm{C}$ before desiccation had minor effect on cryosurvival (Toldam-Andersen et al. 2007). However, with indoor buds the artificial cold acclimation treatment after collection might be beneficial as it could extend the cold acclimation of the buds and help them to better withstand cryopreservation.

The cryosurvival of buds may be different also because of different dormancy state. The bud burst in our greenhouse usually occurs in February when the indoor temperature in the greenhouse raises due to the sunny days, whereas buds in outdoors are still dormant. Thus, the indoor buds were probably closer the cessation of dormancy than the outdoor buds. However, no signs of bud burst were detected among indoor or outdoor buds when scions were collected.

After cryopreservation, the development of shoots started from primordial axillary buds of the dissected bud explants. In the case of floral buds, this was due to the absence of apical meristem but in vegetative buds due to the damage of apical dome. The physiological or morphological stage of bigger buds may have assisted the axillary meristems to withstand cryopreservation or their developmental stage has been more appropriate to initiate in vitro growth. In general, large explants have advantages over small ones for initiating shoot cultures as they stand better the transfer to in vitro conditions, commence growth more rapidly and contain more axillary buds (George and Debergh 2008). Thus, the on average bigger bud size of outdoor buds compared to indoor ones may have contributed to their better post-cryopreservation recovery in vitro. However, when cryopreserved, the effect of bud size may also be opposite, as small buds may have better survival in cryopreservation (Jenderek et al. 2017). This assumption is supported by results of a previous study with Malus, as the buds with the smallest volumes had the highest survival of the primary buds when grafted following cryopreservation (Vogiatzi et al. 2011). Moreover, the recovery of Malus buds can be attributable to a secondary bud outgrowth 
(Vogiatzi et al. 2011; Höfer 2015). In the case of cv. Mortti buds, the contribution of bud size, bud type and cold acclimation history of donor plants to the post-cryopreservation recovery is difficult to distinguish as almost all outdoor buds were floral and on average, they were also bigger than indoor buds. Indoor and outdoor buds differed in bud type and size due to the older age and more robust growth habit of outdoor plants.

In the present study, the dormant blackcurrant buds were cryopreserved with their natural moisture content to accelerate the cryopreservation process. The tested protocol was sufficient for the primordial axillary buds to survive and recover via in vitro culture. However, the injuries detected in both indoor and outdoor buds indicated that the moisture content of buds was not optimal for cryopreservation. The pre-desiccation of twigs can be laborious and time-consuming, but it is included in many dormant bud cryopreservation protocols, as a step to decrease the moisture content of buds that can be lethal. It is possible that the pre-desiccation of twigs might reduce the cryodamages in buds and thereby improve the recovery of the buds in vitro. The different thawing methods might also improve the recovery of the buds (Yakuwa and Oksa 1988).

According to our results, the recovery of cryopreserved buds declined after 4 years in cryostorage. Considering the long-term preservation, the decline of recovery was noteworthy, but recovery was still $58 \%$, i.e. more than $40 \%$ which is considered adequate for long term preservation (Forsline et al. 1998; Reed et al. 1998; Jenderek and Reed 2017). Previously, the decline of regrowth rates after 5 years in cryostorage was reported for birch (Betula pendula Roth) (Ryynänen 1999). As the growth rates of birch declined especially for buds with the female catkin, Ryynänen (1999) suggested that the reason for the decline could be the smaller size and the site of vegetative buds in the axils of female catkins. According to Volk et al. (2008), Malus buds had high viability after 10 years of storage in liquid nitrogen vapour, but some accessions had better viability if they were desiccated prior to slow cooling compared to those that were not. Considering the results of those previous studies, it was possible that the decline of recovery of the outdoor buds of cv. Mortti after 4 years cryostorage was due to the moisture content of buds or the small sizes of primordial axillary buds. At the beginning of the in vitro cultivation of control buds in 2011, visual inspections indicated that the first leaves from outdoor buds grew faster than those from indoor buds, but difference in growth rates equalized later. Both indoor and outdoor control buds produced more and bigger shoots than the cryopreserved buds because they commenced growth more rapidly. The hyperhydricity of shoots was more common among control shoots, likely due to their faster growth rate resulting in culture vessels with lots of plant material and elevated humidity. The cryopreserved buds were more prone to the necrosis because of injuries caused by cryopreservation.

As expected, the survival of shoots in vivo was affected by the size and quality (hyperhydricity) of the shoots. The lower survival of control shoot in vivo is likely connected to hyperhydricity that was more common among control shoots than among cryopreserved shoots. Thus, only shoots adequate in size and quality should be transplanted and the others could be used for multiplication. After cryopreservation, the recovery of shoots in vitro to the adequate planting-size is slower from cryopreserved buds than from control buds, but viable shoots can be cultured via established micropropagation practises. However, at the beginning of the in vitro culture of blackcurrant, the initiation point of shoot outgrowth must be carefully observed and the formation of callus avoided to decrease the risk for genetic instability.

After 9 weeks cultivation in vivo, there were more plantlets eligible for further cultivation among "sturdy" indoor shoots than among "sturdy" outdoor shoots. The indoor shoots had grown more vigorously ex vitro which might be related to the fact that the annually pruned indoor donor plants were younger than outdoor ones, which were pruned only in spring 2009. Thus, it is likely that the state of indoor donor plants was better for vegetative propagation than the state of outdoor donor plants, as explants from the juvenile forms of plants are easier to propagate vegetatively than explants from the adult forms of plants (Preece 2008). It is possible that the juvenile state of indoor donor plants improves growth of microshoots in vivo even when cryopreservation precedes in vitro cultivation.

To conclude, according to the results of 1-6 d cryostorage, the tested dormant bud protocol seemed to be applicable for cryopreservation for both indoor and outdoor cultivated blackcurrant buds. The better recovery of outdoor buds may be due to their better cold acclimation or on average bigger bud size, compared to the indoor buds. The recovery of both indoor and outdoor buds was shown through in vitro culture and the recovered microshoots were successfully cultured into viable plants. However, the decline of recovery after the storage period of several years should be taken into account when long term cryopreservation of blackcurrant germplasm is planned. For instance, desiccation of twigs prior to cryopreservation might help to improve the cryosurvival of the buds.

Acknowledgements Open access funding provided by Natural Resources Institute Finland (LUKE). The authors are grateful to Ms Riitta Toivakka and Ms Satu-Marja Virtanen for technical support in laboratory work. Our sincere appreciations are also expressed to Dr. Mauritz Vestberg who took the photos and all persons who helped to collect and process plant material for cryopreservation. 
Author contributions SR, MU and HH designed the research. SR performed the experiments and wrote the paper. JK was responsible on statistical analyses. SK, MV, MU and $\mathrm{HH}$ took part on writing process. All authors read and approved the manuscript.

Funding This research was partly funded by the European Commission, Directorate-General for Agriculture and Rural Development, under Council Regulation (EC) No 870/2004 through Action 071 AGRI GEN RES 870/2004 (RIBESCO) and partly by The Ministry of Agriculture and Forestry, Maiju \& Yrjö Rikalan Puutarhasäätiö and Oiva Kuusisto Säätiö.

\section{Compliance with ethical standards}

Conflict of interest The authors declare that they have no conflict of interest.

Open Access This article is distributed under the terms of the Creative Commons Attribution 4.0 International License (http://creativeco mmons.org/licenses/by/4.0/), which permits unrestricted use, distribution, and reproduction in any medium, provided you give appropriate credit to the original author(s) and the source, provide a link to the Creative Commons license, and indicate if changes were made.

\section{References}

Aronen T, Ryynänen L (2014) Cryopreservation of dormant in vivobuds of hybrid aspen: timing as critical factor. CryoLetters 35:385-394. https://doi.org/10.1007/s/11627-008-9185-3

Benelli C, De Carlo A, Engelman F (2013) Recent advances in the cryopreservation of shoot-derived germplasm of economically important fruit trees of Actinidia, Diospyros, Malus, Olea, Prunus, Pyrus and Vitis. Biotechnology Advances 31:175-185 https:/doi. org/10.1016/j.biotechadv.2012.09.004

Benson EE, Reed BM, Brennan RM, Clacher KA, Ross DA (1996) Use of thermal analysis in the evaluation of cryopreservation protocols for Ribes nigrum L. germplasm. CryoLetters 17:347-362

Debergh P, Aitken-Christie J, Cohen D, Grout B, von Arnold S, Zimmerman R, Ziv M (1992) Reconsideration of the term "vitrification' as used in micropropagation. Plant cell Tiss Organ Cult $30: 135-140$

FAO (2013) Genebank Standards for Plant Genetic Resources for Food and Agriculture. Rome

Forsline PL, Towill LE, Waddel JW, Stushnoff C, Lamboy WF, McFerson JR (1998) Recovery and longevity of cryopreserved dormant apple buds. J Am Soc Hortic Sci 123:365-370

George EF, Debergh PC (2008) Migropropagation. Uses and methods. In: George EF, Hall MA, De Klerk G-J (eds) Plant propagation by tissue culture, 3rd edn. Springer, pp 29-64

Green J, Grout B (2010) Direct cryopreservation of winter buds of nine cultivars of blackcurrant (Ribes nigrum L.). CryoLetters 31:341-346

Grout BWW, Vogiatzi C, Toldam-Andersen TB, Wetten A (2011) An overview of dormant-bud cryopreservation for the ex situ conservation of woody species in a maritime climate, based on experience with Malus cultivars. In: Grapin A, Keller ERJ, Lynch PT, Panis B, Bahillo AR, Engelmann F (eds) Cryopreservation of crop species in Europe: proceedings of the final meeting, vol 871. COST Action, Vienna, pp 68-73. https://doi.org/10.2831/10956
Harvengt L, Meier-Dinkel A, Dumas E, Collin E (2004) Establishment of a a cryopreserved gene bank of European elms. Can J For Res 34:43-55. https://doi.org/10.1139/X03-193

Höfer M (2015) Cryopreservation of winter-dormant apple buds: establishment of a duplicate collection of Malus gerplasm. Plant cell Tiss Organ Cult 121:647-656. https://doi.org/10.1007/s1124 0-015-0735-1

Höfer M, Hanke M-V (2017) Cryopreservation of fruit germplasm. Vitro Cell Dev Biol Plant 53:372-381. https://doi.org/10.1007/ s11627-017-9841-6

Jenderek MM, Reed BM (2017) Cryopreserved storage of clonal germplasm in the USDA national plant germplasm system. Vitro Cell Dev Biol Plant 53:299-308. https://doi.org/10.1007/ s11627-017-9828-3

Jenderek MM, Ambruzs B, Tanner J, Holman G, Ledbetter C, Postman J, Ellis D, Leslie C (2014) Extending the dormant bud cryopreservation method to new tree species. In: Reed BM (ed) Proc. II nd IS on plant Cryopreservation. Acta Hortc 1039: 133-136

Jenderek MM, Tanner J, Ambruzs BD, West M, Postman JD, Hummer KE (2017) Twig pre-harvest temperature significantly influences effective cryopreservation of Vaccinium dormant buds. Cryobiology 74:154-159. https://doi.org/10.1016/j.cryob iol.2016.10.007

Johnston JW, Harding K, Benson EE (2007) Antioxidant status and genotypic tolerance of Ribes in vitro cultures to cryopreservation. Plant Sci 172:524-534

Jokipii S, Ryynänen L, Kallio PT, Aronen T, Häggman H (2004) A cryopreservation method maintaining the genetic fidelity of a model forest tree, Populus tremula L. x P. tremuloides Michx. Plant Sci 166:799-806. https://doi.org/10.1016/j.plantsci.2003.11.107

Kalberer SR, Wisniewski M, Arora R (2006) Deacclimation and reaclimation of coldy-hardy plants: current understanding and emerging concepts. Plant Sci 171:3-16. https://doi.org/10.1016/j.plant sci.2006.02.013

Karhu S, Antonius K, Rantala S, Pluta S, Ryliskis D, Schulte E, Toldam-Andersen TB, Kaldmäe H, Rumpunen K, Sasnauskas A, Strautina S (2012) A multinational approach for conserving the European genetic resources of currants and gooseberry. In Mezzetti B, Brás de Oliveira P (eds) Proc. XXVIII th ICH International berry symposium. Acta Hortc 926: 27-32

Kovalchuk I, Turdiev T, Mukhitdinova Z, Frolov S, Reed BM, Kairova G (2014) New techniques for rapid cryopreservation of dormant vegetative buds. In: Reed BM (ed) Proc. II nd IS on plant cryopreservation. Acta Hortc 1039:137-146

Lambardi M, Benelli C, De Carlo A, Ozudogru EA, Previati A, Ellis D (2011) Cryopreservation of ancient apple cultivars of Vento: a comparison between PVS2-vitrification and dormant-bud techniques. In: Panis B, Lynch P (eds) Proceedings of the first international symposium on cryopreservation in horticultural species. Acta Hortc 908, ISHS pp 191-198

Lloyd G, McCown B (1980) Commercially-feasible micropropagation of mountain laurel, Kalmia latifolia, by use of shoot-tip culture. Proc. Int. Plant Propagation Society 30:421-427

Matsumoto T, Niino T, Shirata K, Kurahashi T, Matsumoto S, Maki S, Itamura H (2004) Long term conservation of Diospyros germplasm using dormant buds by a prefreezing method. Plant Biotechnology 21:229-232

Mattila PH, Hellström J, Karhu S, Pihlava J-M, Veteläinen M (2016) High variably in flavonoid contents and composition between different North-European currant (Ribes spp.) varieties. Food Chem 204:14-20. https://doi.org/10.1016/j.foodchem.2016.02.056

Niedz RP, Bausher MG (2002) Control of in vitro contamination of explants from greenhouse- and field-grown trees. Vitro Cell Dev Biol Plant 38:468-471. https://doi.org/10.1079/IVP2002316 
Oka S, Yakuwa H, Sate K, Niino T (1991) Survival and shoot formation in vitro of pear winter buds cryopreserved in liquid nitrogen. HortScience 26:65-66

Preece J (2008) Stock plant physiological factors affecting growth and morphogenesis. In: George EF, Hall MA, De Klerk G-J (eds) Plant propagation by tissue culture, 3rd edn. Springer, New York, pp 403-422

Reed BM (ed) (2008) Plant Cryopreservation: A practical guide. Springer, New York

Reed BM (2011) Choosing and applying cryopreservation protocols to new plant species or tissues. In: Panis B, Lynch P (eds) Proceedings of the first international symposium on cryopreservation in horticultural species. Acta Hortc 908, ISHS pp 63-370

Reed BM (2017) Plant cryopreservation: a continuing requirement for food and ecosystem security. Vitro Cell Dev Biol Plant 53:285288. https://doi.org/10.1007/s11627-9851-4

Reed BM, Denoma J, Luo J, Chang Y, Towill L (1998) Cryopreservation and long-term storage of pear germplasm. Vitro Cell Dev Biol Plant 34:256-260

Reed BM, Dumet D, Denoma JM, Benson EE (2001) Validation of cryopreservation protocols for plant germplasm conservation: a pilot study using Ribes L. Biodivers Conserv 10:939-949

Reed BM, Engelmann F, Dulloo ME, Engels JMM (2004a) Technical guidelines for the management of field and in vitro germplasm collections. IPGRI Handbooks for Genebanks No. 7. International Plant Genetic Resources Institute: Rome

Reed BM, Kovalchuk I, Kushnarenko S, Meier-Dinkel A, Schoenweiss K, Pluta S, Straczynska K, Benson EE (2004b) Evaluation of critical points in technology transfer of cryopreservation protocols to international plant conservation laboratories. CryoLetters 25:341-352

Reed BM, Schumacher L, Dumet D, Benson EE (2005) Evaluation of a modified encapsulation-dehydration procedure incorporating sucrose pretreatments for the cryopreservation of Ribes germplasm. Vitro Cell Dev Biol Plant 41:431-436

Rehder A (1940) Manual of cultivated trees and shrubs hardy in North America. Portland Oregon. Reprint 1986, Dudley TR (ed) Biosystematics, Floristic and Phylogeny Series vol 1

Ryynänen L (1996) Survival and regeneration of dormant silver birch buds stored at superlow temperatures. Can J For Res 26:617-623

Ryynänen L (1999) Effect of early spring bud type on post-thaw regrowth after prolonged storage. Can J For Res 29:47-52

Ryynänen L, Sillanpää M, Kontunen-Soppela S, Tiimonen H, Kangasjärvi J, Vapaavuori E, Häggman H (2002) Preservation of transgenic silver birch (Betula pendula Roth) lines by means of cryopreservation. Mol Breeding 10:143-152

Ryynänen L, Jokipii S, Häggman H (2008) Controlled Rate Cooling of Silver Birch and Aspen Dormant Bud. In: Reed BM (ed) Plant Cryopreservation: A practical guide. Springer, New York, pp 432-435

Sakai A (1960) Survival of the twig of woody plants at $-196^{\circ} \mathrm{C}$. Nature 185:392-394
Sherlock G, Block W, Benson EE (2005) Thermal analysis of the plant encapsulation-dehydration cryopreservation protocol using silica gel as the desiccant. CryoLetters 26:45-54

Stushnoff C (2014) Cryophysiology of woody plant dormant buds. In: Reed BM (ed) Proc II nd IS on Plant Cryopreservation. Acta Hortic 1039:63-72

Toldam-Andersen TB, Nygaard TB, Krogholm KS (2007) Cryopreservation of dormant buds of apple cultivars in a maritime winter climate. Adv Hort Sci 21:193-197

Towill LE, Bonnart R (2005) Cryopreservation of apple using nondesiccated sections from winter-collected scions. CryoLetters 26:323-332

Towill LE, Ellis DD (2008) Cryopreservation of dormant buds. In: Reed BM (ed) Plant Cryopreservation: A practical guide. Springer, New York, pp 421-426

Towill LE, Widrlechner M (2004) Cryopreservation of Salix species using sections from winter vegetative scions. CryoLetters 25:71-80

Tyler NJ, Stushnoff C (1988a) The effects of prefreezing and controlled dehydration on cryopreservation of dormant vegetative apple buds. Can J Plant Sci 68:1163-1167

Tyler N, Stushnoff C (1988b) Dehydration of dormant apple buds at different stages of cold acclimation to induce cryopreservability in different cultivars. Can J Plant Sci 68:1169-1176

Uosukainen M (1992) Rooting and weaning of apple rootstock YP. Agronomie 12:803-806

Vogiatzi C, Grout BWW, Toldam-Andersen TB, Wulfsohn D (2011) Dormant bud cryopreservation: Secondary buds can affectthe estimation of post-thaw survival. In: Hummer KE (ed.) Proc. XXVIIIth IHC - III rd IS on plant genetic resources. Acta Hortc 918:147-151

Volk GM, Waddell J, Bonnart R, Towill L, Ellis D, Luffman M (2008) High viability of dormant Malus buds after 10 years of storage in liquid nitrogen vapour. CryoLetters 29:89-94

Volk GM, Bonnart R, Waddell J, Widrlechner MP (2009) Cryopreservation of dormant buds from diverse Fraxinus species. CryoLetters 30:262-267

Yakuwa H, Oka S (1988) Plant regeneration through meristem culture from vegetative buds of mulberry (Morus bombycis Koidz.) stored in liquid nitrogen. Ann Bot 62:79-82

Zhumagulova ZhB, Kovalchuck IY, Reed BM, Kampitova GA, Turdiev TT (2014) Effect of preatreatment methods of dormant pear bud on viability after cryopreservation. WASJ 30.330-334 https://doi. org/10.5829/idosi.wasj.2014.30.03.14028

Publisher's Note Springer Nature remains neutral with regard to jurisdictional claims in published maps and institutional affiliations. 